POETRY

\title{
Where the Ugly Men Hide Atheer Al-Khalfa
}

On the printed covers,

Behind backlit screens, In perfect pictures before breathtaking landscapes, In steady jobs with excellent benefits, Under wide firm shoulders and on shaved faces, Under soft spoken words and softer laughs, Walled with A4 frames in comfortable rooms, and in many more places; the ugly man hides. 